\title{
A EXCLUSION TERRITORIAL COMO UNHA FORMA DE MANIFESTACIÓN DOS PROCESOS DE EXCLUSIÓN SOCIAL*
}

\author{
Territorial exclusion as a form of presentation of the social exclusion processes \\ MELCHOR FERNÁNDEZ \\ ORCID 0000-0002-6255-2033 \\ melchor.fernandez@usc.es \\ DOLORES RIVEIRO \\ ORCID 0000-0003-0104-4331 \\ dolores.riveiro@usc.es \\ Grupo de Análise e Modelización Económica \\ Instituto de Estudos e Desenvolvemento de Galicia (IDEGA) \\ Universidade de Santiago de Compostela.
}

\section{RESUME}

A accesibilidade aos servizos básicos é esencial para asegurar a calidade de vida da poboación. Unha distribución equilibrada destes servizos (escolas, centros de saúde, oficinas de farmacia, centros sociais, servizos deportivos, servizos financeiros, supermercados etc.) permite á poboación identificarse co seu espazo máis próximo, aumentando a cohesión social e a interrelación entre o núcleo de poboación e os seus habitantes. De feito, un dos factores que poden provocar ou agravar a exclusión social dos individuos radica na vulnerabilidade, afastamento ou estigma social dos territorios que habitan. Neste traballo reflexionase sobre o concepto de exclusión territorial e a súa relación coa exclusión social, preséntase un método de cuantificación e análise da exclusión territorial e móstranse os resultados da súa aplicación a un servizo público básico, a prestación farmacéutica. Os resultados obtidos mostran que a regulación actual non permite resolver os problemas de acceso ao medicamento de numerosos núcleos de poboación do interior de Lugo e Ourense.

Palabras clave: Exclusión territorial, Exclusión social, Servizos Básicos.

\section{Abstract}

Accessibility to basic services is essential to ensure the quality of life of the population. A balanced distribution of these services (schools, health centers, pharmacy offices, social centers, sports ser-

* Agradecemos os comentarios e suxestións dos avaliadores e dos participantes nos Seminarios de investigación do IDEGA. Este traballo beneficiouse da financiación procedente do Programa de Axudas para a Consolidación e Estruturación de Unidades de Investigación Competitivas do SUG, Xunta de Galicia na modalidade de Grupos de Referencia Competitiva (ED431C 2017/44). Avda. das Ciencias, Chalet n ${ }^{\circ}$, Campus Vida, CP 15782, Santiago de Compostela. 
vices, financial services, supermarkets, etc.) allows the population to identify themselves with their closest space, increasing social cohesion and the interrelation between the population center and its inhabitants. In fact, one of the factors that can cause or aggravate the social exclusion of individuals lies in the vulnerability, social exclusion or stigma of the territories they inhabit. In this paper, we reflect on the concept of territorial exclusion and its relation to social exclusion, we present a method of quantification and analysis of territorial exclusion and show the results of its application to a basic public service, the pharmaceutical services. The results show that the current regulation does not allow to solve the problems of access to the medication of multiply population centers in the interior of Lugo and Ourense.

Keywords: Territorial exclusion, Social exclusion, Basic services.

\section{INTRODUCIÓN}

Un dos grandes retos a nivel demográfico que teñen que afrontar moitos gobernos locais é o envellecemento poboacional. Trátase dun desafío común para gran parte de Europa, e que nas rexións máis rurais convive cun poboamento disperso e unha poboación en declive. Galicia é unha das rexións europeas máis influídas por estes feitos, se ben non afectan a toda a xeografía galega do mesmo xeito. Fronte a un eixe atlántico con elevadas densidades de poboación e unha dinámica poboacional positiva, o interior de Galicia é un amplo territorio onde se combina o envellecemento ${ }^{1}$, a dispersión ${ }^{2}$ e o despoboamento. ${ }^{3}$

Sen dúbida, ofrecer un sistema de servizos básicos de interese xeral, xusto e equitativo, convértese nun reto de enormes dimensións para o conxunto das administracións públicas galegas, que deben tamén buscar a sostibilidade e a eficiencia na provisión destes bens e servizos. Moito máis, cando a dinámica da poboación galega ofrece dous resultados extremos: núcleos que ameazan con quedarse baleiros, fronte a núcleos e concellos que non paran de medrar e atraer mozos doutras areas de Galicia. Cada ano que pasa está máis consolidado o Eixe Atlántico litoral e unha Galicia interior que se despoboa, sen capacidade de renovación demográfica endóxena. No 2017 Galicia sumou 31 núcleos máis ó seu listado de pobos abandonados para acadar un total de 1.726 (o 50\% dos existentes en España). Pero ademais, Galicia conta con 2.103 entidades onde oficialmente só residen unha ou dúas persoas, o $70 \%$ dos núcleos que están a punto de desaparecer en España, o que sitúa a Galicia na cabeza no abandono do rural.

1 A zona máis rural de Galicia é a que presenta unha poboación máis envellecida, cunha media de idade no ano 2017 de 51,4 anos e na que por cada 100 menores de 20 anos hai preto de 275 de 65 e máis anos (Panorama Rural-Urbano, IGE, https://www.ige.eu/web/mostrar_seccion.jsp?idioma=gl\&codigo=0701).

2 Galicia conta con máis de 30.000 entidades de poboación, cerca da metade do conxunto de España, moitas das cales non superan os 100 residentes. En concreto, o $90 \%$ das entidades singulares de poboación contan con menos de 100 residentes, onde viven case 600.000 galegos.

3 Os concellos con menos de 5.000 habitantes perderon en conxunto entre 1999 e 2017 o $20 \%$ dos seus residentes. De feito, o número de entidades totalmente despoboadas pasou de 1.115 en 1999 a 1.726 en 2017. Máis de 5.400 entidades están a punto de ser abandonadas xa que contan con 5 ou menos residentes (en 1999 estas entidades sumaban 3.633 un $33 \%$ menos). 
O declive poboacional que sofre Galicia incide nas oportunidades reais e na calidade de vida das persoas que habitan amplas áreas do seu territorio, o que se presenta como un desafío territorial de equidade e de sostibilidade para o Estado Social. Compre, logo, minimizar e compensar os efectos dun circulo vicioso que relaciona declive demográfico, envellecemento, déficit de servizos socias e despoboamento, círculo que é unha realidade para amplas zonas rurais. Seguramente non sexa posible facer social e economicamente viables todos os territorios en declive demográfico de Galicia, pero moitos deles teñen un potencial real en termos de inclusión social e laboral que debe ser considerado na planificación e nas actuacións desenvolvidas polos poderes públicos.

A accesibilidade aos servizos básicos é esencial para asegurar a calidade de vida da poboación. Unha distribución equilibrada destes servizos (escolas, centros de saúde, oficinas de farmacia, centros sociais, servizos deportivos, servizos financeiros, supermercados etc.) permite á poboación identificarse co seu espazo máis próximo, aumentando a cohesión social e a interrelación entre o núcleo de poboación e os seus habitantes. De feito, un dos factores que poden provocar ou agravar a exclusión social dos individuos radica na vulnerabilidade, afastamento ou estigma social dos territorios que habitan. Esa "exclusión territorial" dáse cando un individuo, en virtude do seu emprazamento xeográfico e das características estruturais deste, atopa diferencias significativas entre as súas posibilidades de acceso aos bens e servizos característicos da sociedade á que pertence e as posibilidades que normalmente ten o resto da poboación.

A partir desta introdución o traballo estrutúrase como segue. No apartado dous discútese o concepto de exclusión territorial e a súa relación coa exclusión social e a pobreza. $\mathrm{O}$ apartado finaliza cunha caracterización dos territorios excluídos socialmente a partir da cal definimos a exclusión territorial, ou o que poida que resulte incluso un termo máis axeitado, os “Territorios en Exclusión”. No apartado terceiro proponse unha metodoloxía de calculo da exclusión territorial a partir da medición da dificultade de acceso físico aos servizos e recursos básicos ao que se ve sometido un territorio pola súa localización xeográfica. O carto apartado ofrece os resultados da aplicación da metodoloxía proposta a un servizo público básico: a prestación farmacéutica. Antes de ofrecer os resultados da aplicación do concepto de exclusión territorial proposto, ponse de manifesto as dificultades dos indicadores xeralmente utilizados para mostrar as dificultades de acceso aos servizos. Os resultados confirman o déficit do servizo en amplías zonas do interior de Galicia, e polo tanto, xustifícase a necesidade dun cambio no mapa farmacéutico para evitar esta situación, cambio que require utilizar criterios de ordenación diferentes aos usados ata agora. O traballo remata cun resumo das principais ideas e conclusións.

\section{POBREZA, EXCLUSIÓN SOCIAL E EXCLUSIÓN TERRITORIAL}

Como acción e efecto de excluír, unha das acepcións de exclusión é a de negar posibilidades. É neste sentido "negativo" no que se usa o termo no ámbito das ciencias 
sociais, falando de exclusión social para referirse á situación dunha persoa ou grupo que non logra satisfacer as súas necesidades básicas ou que está privada de oportunidades de desenvolvemento. En ocasións a exclusión prodúcese por unha acción explícita de discriminación ou segregación de certos individuos dunha sociedade; pero na maioría dos casos, a exclusión ven motivada polas propias condicións de funcionamento do sistema socio-económico, que non permite a certos individuos o acceso aos bens e servizos básicos, sendo o baixo nivel de renda o principal factor de exclusión. Neste sentido, son os individuos, polas súas características persoais ou socio-económicas, os que están en situación de exclusión, e, nas sociedades desenvolvidas, agárdase que o sistema deseñe medidas de inclusión que favorezan a integración social destes individuos excluídos.

No ámbito da política comunitaria, o uso de termo exclusión social, como tal, é relativamente recente. Aínda que nalgúns estados (fundamentalmente en Francia, pero tamén en Alemaña, Holanda e Reino Unido), viña usándose o termo Exclusión Social dende os anos setenta con diferentes significados, non se consolida no discurso e nos textos comunitarios sobre política social ata os anos noventa (Atkinson e Davoudi, 2000); pasando, a partir dese momento, a designar situacións que ata daquela eran cualificadas como marxinación social, necesidade, vulnerabilidade, precariedade ou, máis comunmente, pobreza. A introdución deste novo termo ten moito que ver coa vontade da Comisión Europea de dar unha "dimensión social" á política da Unión a partir do Tratado de Maastrich. A Europa política e económica quere converterse tamén nunha Europa social. En certo sentido, o termo exclusión social parecía ofrecer un concepto menos emotivo, quizais menos entendido e, polo tanto, menos politicamente contencioso que o de pobreza (Silver, 1994). Pero, ao mesmo tempo, o novo concepto tamén permitía un debate máis amplo sobre as causas das situacións de exclusión e, consecuentemente, sobre as posibles solucións e propostas de política.

Este novo concepto para definir ás persoas en situación de "desvantaxe" social pretende considerar aspectos do fenómeno (coma o seu carácter multidimensional, relativo e dinámico) que non estaban contemplados noutros termos empregados anteriormente coma no de pobreza (Arriba González, 2002). A estes aspectos diferenciais do concepto de exclusión social fronte ao de pobreza, Jehoel-Gijsbers e Vroman (2007) suman os de centrarse no aspecto relacional e non só no distributivo, así coma o carácter esóxeno dalgúns dos factores da exclusión social fronte ao carácter máis endóxeno da pobreza a nivel individual ou de grupo. O punto máis relevante da introdución deste novo concepto foi o recoñecemento de que esta "nova pobreza" era resultado de cambios estruturais profundos que afectaban a varias esferas da sociedade. Era neste sentido no que a propia Comisión argumentaba nos seus textos:

"A noción de exclusión social é unha noción dinámica ... Máis nitidamente que a noción de pobreza, que con farta frecuencia se entende só como baixos ingresos, pon o acento no carácter multidimensional dos mecanismos polos cales as persoas e grupos, ou incluso territorios, se ven excluídos da participación... A exclusión social non só fala de insuficiencia de recursos financeiros, nin se limita á mera participación no 
mundo do emprego: faise patente e maniféstase nos ámbitos da vivenda, a educación, a saúde ou o acceso aos servizos. A exclusión social é una realidade multidimensional, polo que a súa extensión explícase polas insuficiencias ou fallos dos servizos que se ofrecen en materia de educación, de formación, de protección social, de saúde ou de vivenda. Estas insuficiencias ou fallos adoitan tender a acumularse, tanto a nivel persoal como dos territorios..." (Comisión das Comunidades Europeas, 1992, p. 7)

Coa introdución do concepto de exclusión social, o foco do debate pasou a estar centrado non soamente na desigualdade da renda e a exclusión material, senón tamén nas dimensións sociais e culturais do proceso de exclusión. Os estudos sobre este tema pasaron a ocuparse non só da pobreza senón do concepto máis amplo de exclusión social, no sentido que se viña dando ao termo na tradición francesa, na que a "solidariedade social" está no centro do discurso, entendendo que a cohesión social é relevante para o benestar social e económico.

\section{Da exclusión social á exclusión territorial}

Algúns dos aspectos considerados pola Comisión e polos estudos mencionados, en canto ao concepto de exclusión social, poñen o acento en cuestións que son relevantes para a definición do que entendemos por situacións de exclusión territorial, aínda que con unha interpretación diferente. Estas consideracións son: (1) a situación de exclusión social non se define só pola falta de recursos económicos; (2) o carácter multidimensional dos mecanismos polos que se pode chegar a unha situación de exclusión social; (3) a relevancia da dificultade de acceso aos servizos no desencadeamento de situacións de exclusión social e (4) o recoñecemento de que a situación de exclusión pódena sufrir territorios, ademais de individuos ou grupos.

En canto aos factores causais das situacións de exclusión social, tanto Atkinson e Davoudi (2000) como os distintos estudos que se levan a cabo por parte da Comisión Europea nos anos noventa no Observatory on National Policies to Combat Social Exclusion ou na Commission on "Non-Monetary Indicators of Social Exclusion" concluén que estes son de varios tipos: sociais (familia, mercado de traballo, participación social, identidade, visibilidade social...); económicos (salarios, seguridade social, aforros, mercado de bens e servizos...); institucionais (xustiza, educación, saúde, dereitos políticos, burocracia...); pero tamén territoriais (demografía-migración, accesibilidade, zonas desfavorecidas...).

En principio, parece que dos estudos da Comisión podería concluírse que, non só as persoas ou grupos, senón os propios territorios poden estar en situación de exclusión, e que esa forma de exclusión territorial está moi condicionada pola dificultade de acceso a servizos e recursos básicos debido, en parte, aos problemas de transporte e comunicacións. Sen embargo, no desenvolvemento das políticas de inclusión social e nos programas de loita contra a exclusión nos distintos períodos de programación, a cuestión territorial non foi considerada deste xeito. 


\section{A análise territorial da exclusión social}

$\mathrm{Na}$ análise da exclusión social é frecuente considerar o feito de que os excluídos socialmente están localizados en áreas particulares (coma os barrios de vivendas sociais), separadas do resto da sociedade, que se converten en espazos excluídos. De forma xeral, cando á exclusión social se lle engaden aspectos territoriais o que se fai é o que podemos chamar unha análise territorial da exclusión social. Esas situacións de exclusión socio-territorial, no sentido de zonas nas que os seus habitantes viven nunha situación de exclusión social ou de concentración espacial da pobreza, vincúlanse ao concepto de marxinación. Non obstante, a orixe da exclusión nestes espazos non é o territorio e a súa falta de acceso a determinados bens e servizos, senón as propias características das persoas e grupos residentes.

Hai unha dimensión territorial da exclusión que se presenta fundamentalmente nas novas formas de urbanización na área metropolitana de algunhas cidades. A creación de novos asentamentos de poboación sen unha planificación adecuada dos servizos básicos necesarios acaba no que se coñece como exclusión urbana. De feito, existe unha ampla literatura que analiza estas situacións (Manadipour et al. (2005), Mansilla e Fuenzalida (2010) ou Jirón et al. (2010)). Esta aproximación esta máis cércana ao concepto de exclusión territorial que pretendemos desenvolver, xa que está relacionado cos problemas de mobilidade e coa dificultade de acceso a servizos e recursos. Pero trátase dun concepto basicamente urbano, que se desenvolve no contexto de nocións coma "cidade dual", non tendo nada que ver coa dispersión da poboación no territorio en núcleos que, por estar afastados dos centros provedores de servizos, se converten en territorios excluídos (Subirats, 2005).

\section{A exclusión social rural}

A análise territorial da exclusión social no sentido visto anteriormente realízase, en xeral, para espazos urbanos ou peri-urbanos. Se ben é certo que é nos suburbios das cidades onde se dan as situacións de pobreza extrema e de grave exclusión social, tamén se recoñece a existencia de pobreza e exclusión no ámbito rural, presentando certas particularidades:

"A exclusión territorial preséntase en forma diferente...en zonas urbanas e rurais. Non hai que desprezar a importancia da pobreza rural, tanto máis preocupante canto que o mundo rural está en plena transformación: tendo en conta a insuficiencia dos equipos $e$ as infraestruturas que se observa nas zonas rurais, as poboacións desfavorecidas das mesmas atópanse dobremente marxinadas..." (Comisión das Comunidades Europeas, 1992, p. 23).

Vemos que a consideración da existencia de servizos e recursos accesibles como determinante das situacións de exclusión no medio rural, é tida xa en conta pola Comisión Europea no ano 1992. Efectivamente, as poboacións desfavorecidas sofren unha 
dobre exclusión, pero a cuestión é que incluso as poboacións que non terían porque ser desfavorecidas de acordo coas súas características persoais poden sofren a exclusión polas dificultades de acceso aos servizos básicos debido á insuficiencia das dotacións e das infraestruturas de transporte ${ }^{4}$. Esas dificultades non deixaron de incrementarse dende os anos noventa.

No informe sobre pobreza e exclusión social en zonas rurais (European Commission, 2008), se ben non se considera a exclusión territorial como tal, aparecen explicitamente os elementos que a definen. En primeiro lugar, o informe distingue entre pobreza en áreas rurais (ou pobreza de persoas rurais) e pobreza de áreas rurais. A estas últimas, non se lles da o significado de que sexan as propias áreas as que sofren unha situación de pobreza e exclusión social, senón que fan referencia á riqueza relativa desas rexións. Entre as debilidades ou problemas específicos das áreas rurais que determinan esa situación de pobreza está o afastamento desas áreas:

"O afastamento é un elemento importante de dificultade nas zonas rurais.... A concentración dos principais servizos nas zonas urbanas pode ter un impacto na calidade de vida dos grupos xa en risco de exclusión social: nos servizos de saúde, instalacións para maiores ou discapacitados, coidado de nenos para mulleres traballadoras, etc. A accesibilidade ás escolas é outra cuestión importante para nenos e pais que viven en áreas remotas. Ademais, nalgunhas zonas rurais remotas, tamén se está dando unha redución de outros servizos públicos e privados (por exemplo, minoristas, oficinas de correos, bancos, coidado de nenos, bibliotecas, Escolas Infantis)" (European Commission, 2008, p. 59).

E o afastamento, combinado coas deficiencias das infraestruturas de transporte, limita o acceso a servizos básicos:

"A existencia de infraestruturas de transporte limitadas segue sendo un problema en moitas rexións rurais, aumentando a distancia aos mercados e, en xeral, aumentando o illamento social de algúns grupos. En particular, en rexións rurais caracterizadas por unha elevada dispersión da poboación e numerosas pequenas aldeas, a provisión de servizos de transporte público tradicional é difícil e moi caro." (European Commission, 2008, p. 61).

No informe sobre pobreza e exclusión social en Escocia elaborado polo Rural Poverty and Inclusion Working Group (2001), indícase que "o acceso a servizos clave é a cuestión que é amplamente aceptada nas comunidades rurais como a principal causa da exclusión social" (p.9). Consideran tamén que "é particularmente importante para aqueles que sofren a pobreza e a exclusión social nas zonas rurais poder acceder a algúns servi-

4 As medidas de exclusión social tratan de identificar non só a aqueles que non teñen recursos, senón tamén a aqueles para os que a non-participación ven explicada por outras causas: discriminación, enfermidade crónica, localización xeográfica... (Burchardt et al., 2002, p. 6). 
zos nas súas propias comunidades, xa que con frecuencia é menos probable que sexan capaces de viaxar para acceder a servizos noutras localidades”. (p.10). Tamén se indica que ese aspecto da pobreza e a exclusión social no rural non se aborda de forma adecuada a través dos indicadores existentes. Pero o que están considerando é que as dificultades de acceso aos servizos básicos agravan os factores comúns que causan a pobreza e a exclusión social, e fan que as persoas desfavorecidas nas zonas rurais resulten dobremente excluídas, pero non definen a un territorio como excluído.

\section{A exclusión territorial}

Se a limitación no acceso a servizos e recursos básicos é o que determina as situacións de exclusión, os territorios (núcleos de poboación) que pola súa localización xeográfica se atopan nesa situación deben ser considerados territorios excluídos socialmente. O concepto de exclusión territorial non debe ser confundido cos aspectos territoriais ou a análise territorial da exclusión social. Non se refire a como se distribúen as persoas en situación de exclusión social no territorio, senón como uns territorios (e, en xeral, as persoas que viven neles) sofren exclusión polo feito de estar localizados neses asentamentos (pola localización do seu lugar de residencia), non polos condicionantes persoais dos seus habitantes, que é o que normalmente determinan a situación de exclusión social (nivel de renda, educación...). Non nos referimos a territorios nos que viven persoas excluídas (a situación defínena as características persoais, "endóxenas”), senón a persoas que viven en territorios en situación de exclusión (a situación defínena as características do territorio, "esóxenas"), de aí que, para referirnos a esta situación, poida resultar máis axeitado o termo "Territorios en Exclusión".

Podemos definir os territorios en exclusión tamén en termos de "carencias" ou "dificultades de acceso". Pero neste caso a dificultade non está motivada porque os individuos non dispoñen dos suficientes "recursos" (ingresos, formación, cultura, saúde...) que lles permitan acceder aos bens e servizos básicos, senón que é a localización da residencia dos individuos e a localización dos servizos o que dificulta o acceso. Definida desta forma, a exclusión territorial dunha entidade de poboación non está determinada polo seu tamaño, senón pola súa localización e as súas redes de comunicación co resto da súa contorna.

Cando nos referimos á exclusión territorial, son os territorios os que están en situación de exclusión, sendo precisamente ese o motivo polo que as persoas deixan de vivir neles; porque esas persoas, coas súas características socio-económicas, deixan de estar excluídas e poden exercer todos os seus dereitos cidadáns cando trasladan a súa residencia a outro lugar no que non hai problemas de accesibilidade física aos servizos e recursos básicos. Aínda que nos estudos sobre a exclusión social en zonas rurais se ten en conta expresamente a exclusión territorial, nin no diagnóstico dos factores de risco nin na proposta de solucións (Comisión Europea, 2000; European Commission, 2008), vivir nun territorio en exclusión contribúe directamente a eses factores de risco e, polo tanto, non forma parte das propostas de intervención en materia de inclusión social. 


\section{A CUANTIFICACIÓN DA EXCLUSIÓN TERRITORIAL}

Como foi discutido no apartado anterior, o que determina a exclusión territorial é a dificultade de acceso aos servizos e recursos básicos ao que se ve sometido un "territorio" pola súa localización xeográfica. Abordar a cuantificación da exclusión territorial supón, en primeiro lugar, definir cales son as "unidades territoriais" obxecto da análise. En segundo lugar, identificar os servizos e recursos básicos a ter en conta e, por último, abordar a cuestión da accesibilidade (que se entende por un servizo accesible e cal é a medida da accesibilidade).

\section{Unidade poboacional obxecto da análise}

A efectos da exclusión no acceso aos servizos, o ámbito territorial relevante é o das entidades singulares de poboación ${ }^{5}$. Non obstante, os estudos da Comisión sobre os aspectos territoriais da pobreza e a exclusión social utiliza agregacións territoriais superiores como as Comunidades Autónomas (NUT II) ou as provincias (NUT III). Ambas referencias territoriais son demasiado amplas cando o obxectivo é analizar a accesibilidade das persoas aos servizos básicos. Dentro dos limites dunha Comunidade Autónoma, dunha provincia ou mesmo dun concello, nin as persoas nin os servizos están uniformemente distribuídas en todo o territorio. Ambos (persoas e servizos) agrúpanse en "núcleos"6 (entidades de poboación) que, administrativamente, poden forman parte dunha unidade administrativa superior (concello) e que se distribúen nel territorialmente. Pero non todos os núcleos dunha mesma unidade administrativa (concello, provincia, rexión) están provistos de todos os servizos e recursos básicos. Cando nun núcleo non existe oferta de servizos, as persoas que habitan nel teñen que desprazarse a outro núcleo para poder acceder a eses servizos. Cando a distancia entre ambos núcleos supera un umbral mínimo é cando dicimos que ese núcleo de poboación está "territorialmente excluído".

As persoas que viven en entidades territorialmente excluídas, poden sufrir ou non unha situación de exclusión social en función das súas características socio-económicas; pero, en calquera caso, a localización xeográfica da entidade na que viven constitúe un factor "esóxeno" que contribúe ao risco de sufrir exclusión social. Ante esta situación, ¿que resposta podemos agardar? O comportamento racional levaría a eses individuos a tomar a decisión de localizar a súa residencia noutro lugar, xa que o seu benestar aumentaría polo feito de trasladarse. Se este fose o caso, observariamos unha concentración da poboación en núcleos con fácil acceso a servizos e recursos, despoboándose progresivamente os territorialmente excluídos. Por suposto, non queremos dicir que todos os

5 Unha entidade singular de poboación é calquera área habitable do termo municipal, habitada ou excepcionalmente deshabitada, claramente diferenciada dentro do mesmo, e que se coñece por unha denominación específica que a identifica sen posibilidade de confusión.

6 O Núcleo de poboación segundo o Nomenclator é un conxunto de polo menos dez edificacións, que están formando rúas, prazas e outras vías urbanas. O número de edificacións poderá ser inferior a 10, sempre que a poboación que habita as mesmas supere os 50 habitantes. 
territorios que se despoboaron en Galicia ao trasladar os seus habitantes a súa residencia a outras localizacións estivesen en situación de exclusión territorial. É ben sabido que existen outros factores determinantes, nomeadamente a falta de actividade económica, pero, sen dúbida, a exclusión territorial foi e segue sendo un factor importante.

\section{Servizos e recursos básicos}

Cando a Comisión Europea pasa a centrar a política social no concepto de exclusión social, recoñece o carácter multidimensional da exclusión, que se manifesta nos ámbitos dos recursos financeiros, o emprego, a vivenda, a educación, a saúde ou o acceso aos servizos (Comisión das Comunidades Europeas, 1992, p. 7). No Consello Europeo de Lisboa (2000) proponse uns indicadores cuantitativos e comparables, que serán acordados no Consello de Laeken (2001) co obxectivo de monitorear os resultados das políticas que os Estados membro debían implementar para loitar contra a pobreza e a exclusión social. Os indicadores propostos tratan de informar sobre as principais dimensións da exclusión social e divídense en: exclusión económica (carencia de recursos materiais), exclusión educativa, exclusión laboral, exclusión sanitaria e exclusión residencial. Pola súa parte, a Plataforma contra a Pobreza e a Exclusión Social, no contexto da Estratexia Europea 2020, considera as mesmas cinco dimensións que contemplaban os indicadores de Laeken, incorporando, ademais, o acceso a contas bancarias básicas.

Os indicadores considerados pola Comisión son indicadores de resultado que miden a situación de participación das persoas nas distintas dimensións. Miden a exclusión social das persoas, non do territorio. En todos os casos, hai unha dimensión económica da exclusión (que comprende a renda e o emprego), que se manifesta en privacións "materiais", unha dimensión residencial (vivenda) e unha dimensión que se corresponde en parte co que Jehoel-Gijsbers e Vroman (2007) denominan "acceso inadecuado a provisións públicas e semi-públicas" (dereitos sociais), entendendo por tales os obstáculos á: saúde, educación (especialmente dos nenos), vivenda, asistencia xurídica, servizos sociais, etc. e certos servizos comerciais (como a banca e os seguros). Este tipo de exclusión a dereitos sociais non se refire a aspectos estritamente sociais ou relacionais, senón que ten que ver tamén con aspectos distributivos (coma a exclusión económica), aínda que neste caso, en lugar de ser un aspecto distributivo "material", sexa un aspecto distributivo "non-material".

Cando analizamos a exclusión territorial o que queremos analizar non é a falla de recursos materiais asociada, en xeral, a problemas laborais. Por suposto que a localización xeográfica da residencia pode dificultar o acceso ao traballo, (tal vez a falla de actividade económica teña sido a principal causa de despoboamento do rural galego), pero o que queremos ter en conta son as dificultades de acceso a bens e servizos básicos, non por falla de recursos económicos dos residentes senón pola ausencia do servizo no entorno próximo. As dimensións que consideramos relevantes na exclusión territorial son o acceso a: educación, servizos sanitarios, servizos sociais e servizos comerciais. Cada unha das dimensións pode comprender varios servizos e recursos. 


\section{Definición e medida da accesibilidade}

A accesibilidade a un servizo pode definirse, en xeral, polo grao no que ese servizo pode ser usado (ou accedido) polos usuarios. Desta maneira, a accesibilidade pode ser medida polas dificultades, do tipo que sexan, asociadas ao seu uso. Dende o punto de vista dos usuarios, esas dificultades poden ser varias, estando relacionadas, por unha parte, coas características socioeconómicas dos mesmos e, por outra, coas barreiras xeográficas ou espaciais derivadas da distribución no territorio, tanto dos servizos coma dos usuarios. Polo tanto, a accesibilidade no ámbito dos servizos sociais, sanitarios ou, mesmo, educativos pode ser entendida dende varias perspectivas: a financeira, é dicir, que parte da poboación está cuberta e que gama de servizos está dispoñible a través dun sistema financiado por fondos públicos; a informativa ou de acceso da poboación á información sobre servizos e profesionais, incluída a súa mobilidade; e a física, é dicir, o tempo que tarda o usuario en acceder ao servizo.

No caso da exclusión territorial, son as barreiras de tipo físico as relevantes para definir o grao de accesibilidade (ou, polo contrario, o de exclusión) dunha entidade de poboación en relación a un determinado servizo. É a este ámbito da accesibilidade, á accesibilidade "espacial", que tamén se denomina as veces "xeográfica", á que nos referimos neste traballo. Na nosa análise, ao igual que na maioría dos estudos, ${ }^{7}$ a accesibilidade relaciónase coa distancia entre dous puntos (orixe e destino), optando por un modelo de espazo xeográfico discreto, onde os desprazamentos entre ditos puntos só se poden realizar a través de determinadas vías de transporte ou comunicación. ${ }^{8}$ En particular, a accesibilidade dunha entidade de poboación aos distintos servizos e recursos é avaliada mediante o mínimo tempo necesario para percorrer a distancia dende a entidade de poboación ao servizo dese tipo máis preto, isto é, seguindo a "ruta óptima", e tendo en conta o transporte privado por estrada.

A situación de exclusión territorial dunha determinada localización depende do que se entende como "normal" ou "aceptable" en cada sociedade en cada época. De maneira xeral, consideramos que unha entidade de poboación ten accesible un servizo se o ten dispoñible na mesma entidade ou noutra a que é posible desprazarse en coche en menos de 15 minutos. Así, as entidades de poboación nas que para dispoñer dun servizo os seus habitantes deben desprazarse a outra entidade tardando máis de 15 minutos, cualificámolas como territorialmente excluídas. ${ }^{9}$

$7 \quad$ Na literatura sobre accesibilidade de servizos encontramos diferentes definicións e medidas da accesibilidade espacial. Por exemplo, para os servizos sociais e sanitarios véxase, entre outros, Gulliford e Morgan (2003), Guagliardo (2004); Higs (2004); Bosque e Moreno (2012).

8 A medición da accesibilidade proponse mediante o tempo necesario para percorrer a distancia a través da rede de vías públicas, fronte a unha distancia cartesiana (euclidiana o Manhattan). Se ben no caso de zonas urbanas, con distancias cortas, a correlación entre as distancias cartesianas e as distancias polas vías de comunicación é alta, non o é para as zonas rurais (Apparicio et al, 2008).

9 Podemos graduar a exclusión, considerando diferentes distancias de referencia, por exemplo, 15 minutos e 30 minutos. Tamén se pode fixar unha "distancia de referencia" distinta para cada un dos servizos, en base ao tipo de servizo, ao perfil do usuario tipo, á frecuencia de uso, etc. 
$\mathrm{Na}$ análise non se ten en conta que os servizos que se ofertan nas diferentes localizacións poden ser de diferente calidade ou dar diferente nivel de servizo. Podería darse o caso de que, aínda dispoñendo do servizo, os potenciais usuarios non lle conceden a calidade suficiente ao servizo ou non se poidan permitilo, de maneira que seguen a estar nunha situación de exclusión, neste caso persoal ou endóxena. A percepción de diferente calidade dun servizo pode ser subxectiva, pero tamén hai datos obxectivables que permiten outorgar maior ou menor calidade ao servizo e que poderían incluírse na análise. ${ }^{10}$

\section{EXCLUSIÓN TERRITORIAL: APLICACIÓN Á PRESTACIÓN FARMACÉUTICA EN GALICIA}

A continuación mostramos a aplicación da medida proposta a un dos servizos considerados como básicos: a prestación farmacéutica. O obxectivo é analizar un caso concreto que ten particularidades que permiten visualizar as dificultades da posta en práctica do concepto de exclusión territorial. A modificación do mapa farmacéutico galego en 2017, quince anos despois da última modificación, é unha oportunidade única para contrastar a metodoloxía proposta. A regulación da apertura de 41 novas oficinas de farmacia para asegurar a atención farmacéutica a toda a poboación galega supón recoñecer oficialmente a existencia dun problema de accesibilidade, coñecido polas poboacións afectadas pero oculto na información oficial.

\section{As medidas tradicionais de accesibilidade ás farmacias}

Segundo os datos ofrecidos polo Consejo General de Colegios Oficiales de Farmacéuticos, CGCF (2014), o modelo español de ordenación farmacéutica ten como resultado que o $99 \%$ da poboación española dispoña de oficina de farmacia no propio concello onde reside, o que se considera como suficiente garantía para que o medicamento chegue en condiciones de igualdade ao cidadán tanto no medio urbano como no medio rural. Este resultado está en liña coas estimacións realizadas con anterioridade por Antares Consulting (2011) que estima con referencia ao ano 2007 que o 87\% da poboación española dispón dunha oficina de farmacia a menos de 250 metros do seu domicilio e o $97,3 \%$ a unha distancia igual ou menor a $5 \mathrm{~km}$, empregando para desprazarse ata ela entre 2,5 e 6 minutos. Estes datos, situarían a cobertura en España nunha situación cércana a óptima e, por suposto, cunha accesibilidade ás farmacias moi superior a de outros países do noso entorno ${ }^{11}$.

10 Por exemplo, no caso dun centro de saúde, os usuarios poden ter diferente percepción sobre a "calidade da atención", pero datos coma a amplitude do horario de atención ou a existencia de pediatra no centro permiten obxectivar diferenzas na calidade de servizo.

11 De acordo cunha enquisa do Pharmaceutical Group of European Union (PGEU), o 98\% dos europeos poden acudir a unha farmacia en menos de 30 minutos, pero só o $58 \%$ dos entrevistados indicaron que tiñan unha farmacia a menos de 5 minutos do seu domicilio (ver Sustainable European Community Pharmacies Part of the Solution). 
Vexamos cal é a situación en Galicia e nas CC. AA. limítrofes (Táboa 1). Ao igual que no conxunto de España, o número de municipios no ano 2013 sen oficina de farmacia é moi reducido ( 2 de $315^{12}$ ). Se consideramos que un servizo é accesible si esta presente no concello de residencia ou en algún dos concellos colídante, o $100 \%$ da poboación galega tería poucas dificultades para acceder aos servizos de farmacia e non sería necesaria ningunha modificación do mapa farmacéutico. ${ }^{13}$ De feito, utilizando este indicador a situación en Castela-León seria moito máis desfavorable que en Asturias ou Galicia.

Táboa 1. Comparación distribución oficinas de farmacia por CC.AA, 2013

\begin{tabular}{|l|c|c|c|c|}
\hline & $\begin{array}{c}\text { Número } \\
\text { municipios }\end{array}$ & $\begin{array}{c}\text { Poboación } \\
\text { concellos sen } \\
\text { oficina }\end{array}$ & $\begin{array}{c}\text { Tamaño medio } \\
\text { municipal } \\
\text { (poboación) }\end{array}$ & $\begin{array}{c}\text { Poboación por } \\
\text { oficina na cc. aa. }\end{array}$ \\
\hline CASTILLA-LEON & 2.248 & $7,70 \%$ & 1.133 & 1.557 \\
\hline ASTURIAS & 78 & $0,40 \%$ & 13.812 & 2.357 \\
\hline GALICIA & 315 & $0,12 \%$ & 8.830 & 2.079 \\
\hline
\end{tabular}

Fonte: Elaboración propia a partir de CGFC (2014) e Instituto Nacional de Estadística.

As medidas de accesibilidade baseadas na "dispoñibilidade do servizo nun ámbito territorial", son un aceptable indicador si toda a poboación da unidade territorial considerada ten idéntica accesibilidade, o cal solo é posible si tanto a poboación como os servizos se concentran nun único núcleo de poboación. ${ }^{14}$ Neste caso, a accesibilidade sería independente da superficie do concello, da súa distribución en unha ou varias entidades de poboación e das distancias existentes entre elas. Pero isto non é o que ocorre si a poboación do concello se distribúe en varios núcleos, que ademais poden distar do núcleo principal varios quilómetros, unha realidade común en moitos concellos de Asturias e Galicia. Calculando o número de habitantes por farmacia para as tres comunidades (última columna da táboa 1) comprobamos o sesgo que introduce o indicador de accesibilidade proposto dende CGFC. Agora sería a poboación de Castela e León a que contaría cunha maior accesibilidade, con solo 1.557 habitantes por Farmacia, moi lonxe de Asturias e Galicia, con case un $50 \%$ máis de residentes por farmacia.

Podemos ilustrar a falta de consistencia deste indicador modificando a unidade territorial de referencia. Se consideramos a parroquia (nivel intermedio de división te-

12 A finales de 2013, só Navia de Suarna en Lugo e Esgos en Ourense non contan cunha oficina de farmacia, é dicir, o $0.63 \%$ dos municipios e o $0.05 \%$ da poboación.

13 O mapa farmacéutico galego vixente en 2018 conta con máis de quince anos de antigüidade. O número de farmacias (1.345) e a súa distribución xeográfica non tivo ningún cambio significativo dende 2013.

14 Este suposto pode ser unha boa aproximación para o conxunto de España e especialmente para CastelaLeón, onde o $60 \%$ dos concellos conta cunha única entidade de poboación. Mentres no conxunto de España o $75 \%$ da poboación viven na capital do concello, en Galicia só o fan o 25\% dos residentes. 
rritorial), o mapa de accesibilidade as oficinas de farmacia en Galicia modifícase considerablemente, ao igual que o volume de poboación con problemas de acceso. Fronte ao $0,12 \%$ de galegos que non contan con farmacia no concello, pasamos a case un $26 \%$ da poboación, que son os que residen en parroquias onde non existe ningunha farmacia. O máximo porcentaxe de poboación excluída acadaríase en Lugo, con case o 41\%, e o menor en Pontevedra, co $19 \%$ da poboación vivindo en parroquias sen farmacia (mapa 1). Non obstante, medir a accesibilidade tomando como referencia a parroquia pode que tamén sexa unha medida pouco apropiada. As parroquias igual que os concellos poden estar formadas por varios núcleos e por outra banda as distancias entre parroquias poden ser facilmente salvables.

\section{A cuantificación da exclusión territorial: unha alternativa baseada na distancia}

Soamente con medidas baseadas na distancia entre puntos (orixe e destino), poden solventarse os problemas de medición da accesibilidade indicados nos parágrafos anteriores. Por suposto, esta opción require dun maior esforzo de calculo,,$^{15}$ perfectamente asumible dado o actual desenvolvemento dos Sistemas de Información Xeográfica e as facilidades de calculo ofrecidas polos actuais ordenadores persoais. A combinación de diferentes técnicas de análise espacial permite o cálculo de "rutas óptimas" empregando o algoritmo de Dijkstra (ou de camiños mínimos, Dijkstra, 1959) a partir da información sobre os atributos concretos das vías de comunicación existentes (tipo de vía, velocidade media de cada un dos tramos, as restricións de acceso, de xiro, os sentidos de circulación... $)^{16}$ e da información sobre as ubicacións das entidades singulares de poboación e do servizo de que se trate. ${ }^{17}$ En resume, para valorar a accesibilidade da poboación que reside nun determinado núcleo ao servizo farmacéutico, mídese a distancia entre un nodo de orixe (centroide do núcleo de poboación) e un de destino (localización xeográfica da oficina de farmacia) a través dunha rede (a red de carreteras), considerando que os individuos se desprazan en vehículo privado e do xeito máis eficiente (o máis rápido).

15 Por exemplo, no caso das oficinas de farmacia é necesario calcular as rutas óptimas para a combinación das 30.000 entidades singulares de poboación e as 1.345 oficinas de farmacia.

16 A información relativa a rede de carreteras de Galicia é a proporcionada á partir da cartografia adquirida a empresa NAVTEQ (hoxe propiedade de Ford), actualizada para o ano 2017. O sistema recopila e verifica a xeometría das carreteras e ata 260 atributos das vías de comunicación.

17 O sistema de información xeográfica utiliza unha cartografía propia de Entidades Singulares de poboación obtida a partir do cruce e verificación dos datos procedentes da Infraestructura de datos espaciais de Galicia, o Catastro, o Ministerio de Fomento, correos, o nomenclátor do instituto nacional de estatística (INE) e o nomenclátor xeográfico de concellos e entidades de poboación do Instituto Xeográfico Nacional (IGN). A localización dos nodos de destino obtívose mediante a xeocodificación por dirección postal de todas as oficinas de farmacia, obtida a partir da información disponible na paxina web do SERGAS e de información adicional ofrecida polos colexios farmacéuticos provinciais. 
Mapa 1. Accesibilidade a Farmacia en 2013 (unidade territorial de análise = parroquia)

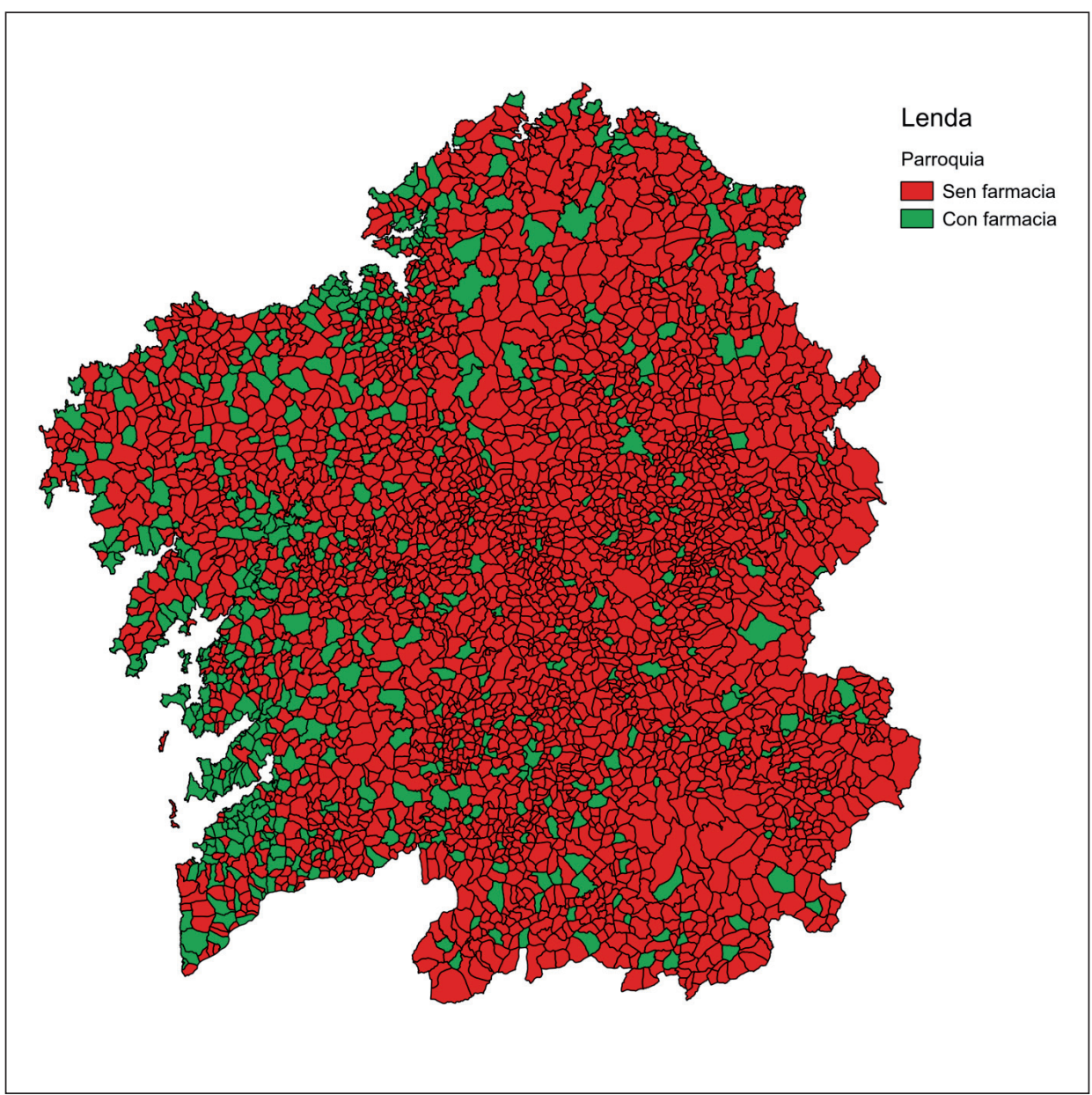

Fonte: Elaboración propia.

Unha vez deseñado o indicador, é preciso determinar a distancia (ou tempo) que define a dificultade ou imposibilidade de acceso a unha farmacia. A resposta a esta cuestión non é única. ${ }^{18}$ Unha solución é mostrar diferentes tempos que poden considerarse relevantes, representando distintos niveis de accesibilidade.

18 É moi difícil chegar a un acordo sobre o límite (neste caso, distancia-tempo) que impide ou dificulta a utilización dun servizo. No caso das farmacias, na literatura contamos con exemplos que utilizan dende 250 metros (distancia mínima entre farmacias) para as cidades ata 5-10 km nas áreas rurais (en coche). Por exemplo, Law et al (2008) nun estudio aplicado a Ontario, toman 800 metros (andando) para as cidades e $5 \mathrm{~km}$ (en coche) para áreas rurais. 
Os cálculos realizados (Táboa 2) mostran que case o 3,5\% da poboación galega tería grandes dificultades de acceso físico ás farmacias (esta residindo a máis de 15 minutos en coche da oficina de farmacia máis próxima). ${ }^{19}$ Con estes datos podemos concluír que a accesibilidade ás farmacias é un problema relevante en Galicia, o cal non pode ser apreciado na súa verdadeira dimensión cando a análise utiliza como unidade de referencia o concello e como criterio de accesibilidade a existencia de farmacia no propio municipio.

As importantes diferenzas territoriais en termos de accesibilidade poden apreciarse visualmente no mapa 2. En Lugo, o $10 \%$ da poboación debe desprazarse máis de 15 minutos en coche para acceder a unha farmacia, mentres que en Ourense esa porcentaxe baixa ata o 5,2\%. As dificultades son na Coruña e en Pontevedra significativamente inferiores. Na Coruña o $1,96 \%$ e en Pontevedra o $1,15 \%$ dos residentes teñen que realizar un desprazamento en coche superior aos 15 minutos para chegar a unha farmacia. ${ }^{20}$

Táboa 2. Poboación a máis de 15 minutos dunha Oficina de Farmacia

\begin{tabular}{|l|c|c|}
\hline & Poboación & Peso no total \\
\hline Galicia & 83.752 & $3,05 \%$ \\
\hline A Coruña & 22.232 & $1,96 \%$ \\
\hline Lugo & 34.094 & $9,95 \%$ \\
\hline Ourense & 16.496 & $5,12 \%$ \\
\hline Pontevedra & 10.930 & $1,15 \%$ \\
\hline
\end{tabular}

Fonte: Elaboración propia a partir de CGFC (2014) e Instituto Nacional de Estadística.

19 Temos que ter en conta que, dada a elevada dispersión e reducido nivel de demanda, a rede de transporte público nas áreas rurais galegas é moi deficiente, o que na práctica supon que distancias relativamente pequenas en vehículo propio poden ser difícilmente superables en transporte público.

20 Dadas as características demográficas de cada provincia, as diferenzas agravaríanse considerablemente se, tal como fai Lin (2004), nun traballo sobre accesibilidade a farmacias en Illinois, ponderásemos a distancia pola porcentaxe de poboación maior en cada centroide, tratando de aproximar a accesibilidade "efectiva" ou "revelada". 
Mapa 2. Exclusión territorial das entidades de poboación de Galicia ás Oficinas de Farmacia, distancia de referencia de 15 minutos

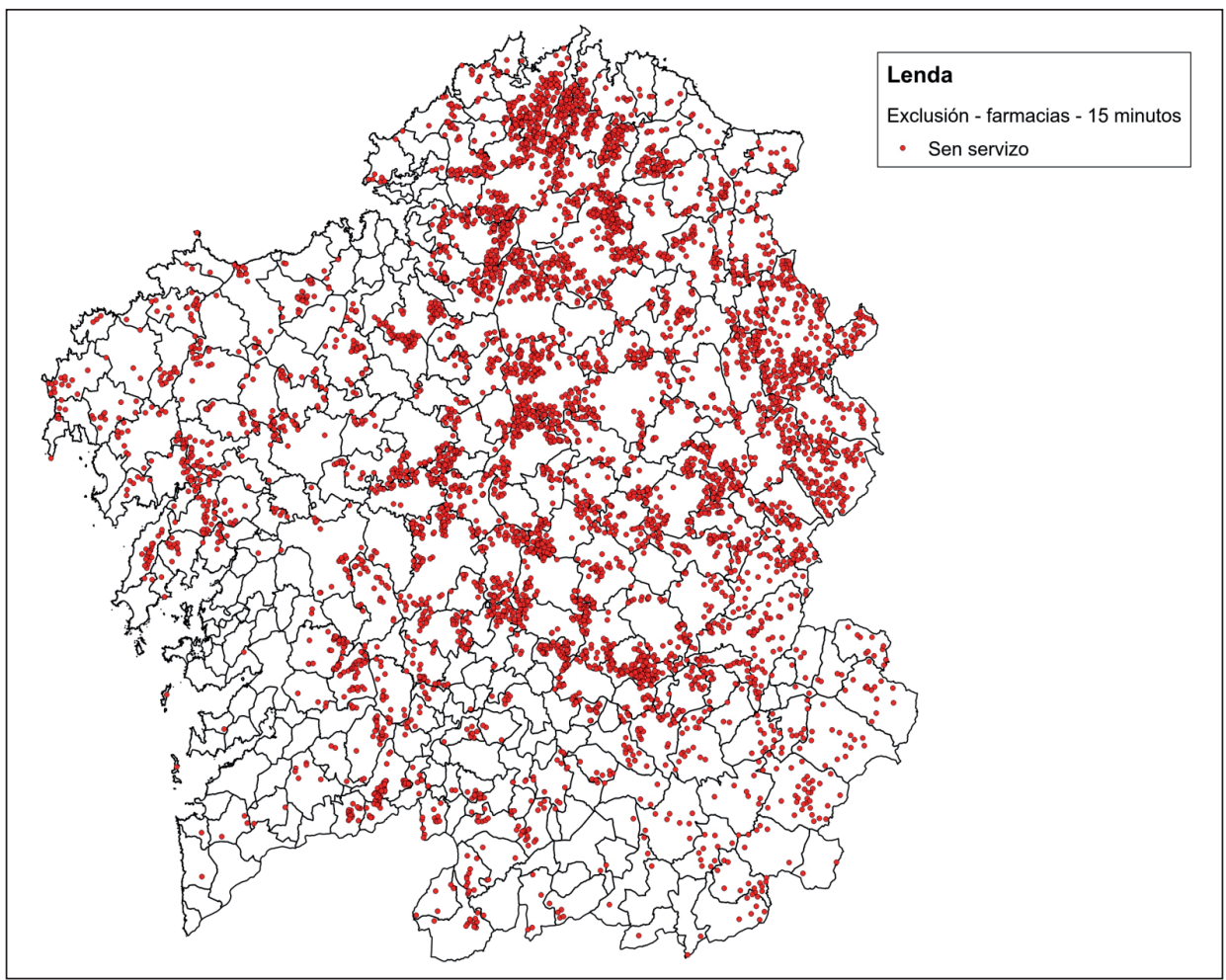

Fonte: Elaboración propia.

\section{CONCLUSIÓNS}

A falta de acceso aos servizos básicos pode agravar ou incluso provocar a exclusión social dos individuos. As dificultades de acceso a estes servizos obedecen a múltiples causas que teñen solucións moi diferentes. Identificar as causas para cada caso concreto é un requisito previo para que a actividade das administracións públicas poda ter os efectos desexados na calidade de vida da poboación. Para mellorar a eficiencia das políticas territoriais é esencial identificar todas aquelas situacións onde as dificultades de acceso aos servizos básicos é por causa do emprazamento xeográfico dos individuos e non polos condicionantes persoais dos mesmos (nivel de renda ou nivel educativo). Por iso, propoñemos un método para identificar o que denominamos como exclusión territorial. Son os territorios, e non as persoas, os excluídos. Non nos referimos a territorios nos que viven persoas excluídas, senón a persoas que viven en territorios en situación de exclusión (a situación defínena as características do territorio) de aí que, para referirnos a esta situación, 
poida resultar máis axeitado o termo “Territorios en Exclusión”. É dicir, poden existir cidadáns que sufran unha dobre exclusión, polas súas características sociodemográficas e polas condicións do territorio onde habitan.

Definimos os territorios en exclusión en termos de "carencias" ou "dificultades de acceso" dos seus residentes aos servizos básicos, sempre e cando estas dificultades teñan orixe na distancia física existente entre a residencia e a localización dos servizos. Así, un territorio en exclusión tenderá a ser abandonado polos seus residentes, pois estes deixarían de estar excluídos e poderían exercer todos os seus dereitos cidadáns cando trasladan a súa residencia a outro lugar no que non hai problemas de accesibilidade física aos servizos e recursos básicos. Tratase dunha situación de exclusión "facilmente" reversible a través da mobilidade, quizais por iso non teña tido o recoñecemento que debera nos protocolos de actuación das administracións públicas.

No caso da poboación galega, a elevadísima dispersión en pequenos núcleos dificulta o acceso aos servizos públicos e privados (non se acada niveis de demanda apropiados para garantir unha oferta eficiente) o que pode provocar situacións de exclusión territorial que ata agora non se cuantificaron correctamente. Para mostrar este feito diferencial e as dificultades da súa identificación neste traballo analizamos a situación de accesibilidade da poboación galega en relación a prestación farmacéutica.

O abandono do concello como unidade territorial de análise permite mostrar como a accesibilidade espacial á atención farmacéutica en Galicia dista de ser tan elevada como oficialmente se anuncia, presentando ademais importantes desequilibrios territoriais. Ao considerar unidades territoriais menores (as entidades singulares de poboación), podemos mostrar como existen importantes dificultades para acceder á prestación farmacéutica para unha amplía parte do territorio galego, especialmente nas áreas rurais interiores das dúas provincias orientais. O problema acada neste caso unha maior complexidade dado que estes núcleos contan cunha poboación maioritariamente ancián, cunha maior frecuencia de uso desta prestación. Este resultado podería xustificar un cambio na regulación actual co obxectivo de considerar, ademais da densidade e volume da poboación, o seu grado de dispersión e, polo tanto, as verdadeiras barreiras de acceso dos usuarios ao servizo que ofrecen as farmacias.

A revisión en 2017 do mapa farmacéutico galego (Decreto 127/2017, de 23 de noviembre) para incluír a apertura de 41 novas oficinas de farmacia é un recoñecemento ás dificultades de acceso actual á prestación farmacéutica. Pero os criterios de asignación de oficinas de farmacia teñen sido os mesmos que no mapa vixente (con predominio do criterio de numero de residentes), o que pode ser insuficiente para corrixir a situación de exclusión do servizo identificada neste traballo. Cando se resolva o concurso e podamos identificar as localizacións concretas das novas farmacias poderemos facer unha nova avaliación da situación, pero algúns indicios poñen en dubida a medida en relación á mellora da cobertura e accesibilidade da poboación que tiña maiores dificultades de acceso. Por un lado só 24 das 41 novas farmacias se abrirán en parroquias sen farmacia actualmente e só 9 abrirán nas provincias de Lugo e Ourense, onde identificamos os núcleos de 
poboación con maiores dificultades. Ademais, no caso das dúas provincias interiores as novas farmacias localizaranse alí onde aumentou a poboación (Pereiro de Aguiar, Allariz e Verín, en Ourense e Friol, Burela, e Ribadeo en Lugo), onde xa contaban con farmacia a menos de 15 minutos en coche. Mención a parte para Esgos e Negueira de Muñiz que xa estaban no mapa anterior, pero non estaban activas.

A consideración da parroquia como unidade territorial de análise dificulta acadar unha mellor cobertura. É necesario un cambio na regulación actual para considerar a dispersión da poboación (núcleos de poboación e a distancia entre eles) e non só a súa densidade e volume. Modificar a unidade territorial de referencia podería mellorar sensiblemente a accesibilidade real da poboación galega a atención farmacéutica. A outra solución extrema, a liberalización total do servizo, vista a experiencia vivida nos últimos anos co proceso de axuste do sector financeiro, podería ser moi contraproducente (Fernández e Meixide, 2013 ou Maudos, 2018). O abandono de grandes áreas rurais por parte da banca comercial é una realidade que ten deixado sen servizos financeiros no seu entorno máis próximo a unha porcentaxe cada vez maior da poboación galega, situación que non parece aínda estar estabilizada. 


\section{BIBLIOGRAFÍA}

Antares Consulting (2011): Dossier de Valor de la Distribución Farmacéutica en España. Aportación y Costes, ANTARES Consulting, Madrid.

Apparicio, P.; Abdelmajid, M.; Riva, M. and Shearmur, R. (2008): "Comparing alternative approaches to measuring the geographical accessibility of urban health services: Distance types and aggregation-error issues", International Journal of Health Geographics 7:7.

Arriba González, A. (2002): "El concepto de exclusión en política social”, Unidad de Políticas Comparadas (CSIC), Documento de Trabajo 02-01.

Atkinson, R. e S. Davoudi (2000): "The Concept of Social Exclusion in the European Union: Context, Development and Possibilities", Journal of Common Market Studies, vol. 38 (3), pp. 427-48.

Bosque, J. e A. Moreno Jiménez (2012): Sistemas de información geográfica y localización óptima de instalaciones y equipamientos", GeoFocus (Recursos), nº 12.

Burchardt, T., Le Grand, J. e Piachaud, D. (2002): “Introduction” in Hills, J., Le Grand, J. and Piachaud, D. (Eds) Understending Social Exclusion, Oxford University Press.

Comisión de las Comunidades Europeas (1992): "Hacia una Europa de la Solidaridad. Intensificación de la lucha contra la exclusión social y promoción de la integración", COM (92), 542 Final.

CGCOF (2014), Consejo General de Colegios Oficiales de Farmacéuticos, "La distribución de la Farmacia en España".

Dijkstra, E. W. (1959): A note on two problems in connexion with graphs». Numerische Mathematik 1: 269-271. doi:10.1007/BF01386390.

European Commission (1997): Rural Developments. Directorate General for Agriculture (DG VI) CAP 2000. European Commission. Working Document. July 1997.

European Commission (2008): Poverty and Social Exclusion in rural Areas

Fernández, M. e A. Meixide (2013): "La reestructuración bancaria en Galicia: impacto sobre la exclusión financiera territorial”, Comunicación presentada al Congreso Smart Regions for a Smarter Growth Strategy, 21-22 noviembre, Oviedo.

Guagliardo, M. (2004): "Spatial accessibility of primary care: Comcepts, methods and challenges", International Journal of Helth Geographics, 3:3.

Gulliford, M. e M. Morgan (2003): Access to health care, Routledge, London.

Higss, G. (2004): "A Literature Review of the Use of GIS-Based Measures of Access to Health Care Services" Health Services \& Outcomes Research Methodology 5: 119-139.

Jirón, P., Lange, C. e Bertrand, M. (2010): "Exclusión y desigualdad espacial: Retrato desde la movilidad cotidiana", Revista INVI, vol. 25, n 68, pp. 15-57.

Jehoel-Gijsbers, G. e Vroman, C. (2007): Explaining Social Exclusion. A theoretical model tested in the Netherlands, The Netherlands Institute for Social Research. The Hague.

Law, M; A. Dijkstra, A. Douillard e S. Morgan (2011): "Geographic Accessibility of Community Pharmacies in Ontario”, Healthcare Policy, 6(3) March 2011: 36-45. 
Lin, S. J. (2004): “Access to community pharmacies by elderly in Illinois: a Geographic Information Systems analysis", Journal of Medical Systems, vol. 28, n³.

Mandanipour, A., Cars, G. e Allen, J. (2005): Social Exclusion in European Cities. Processes, Experiences and Responses, Routledge.

Mansilla, P. e Fuenzalida, M. (2010): "Procesos de desarrollo urbano-regional y exclusión territorial: Nuevas formas de urbanización en el área metropolitana de Valparaíso. Estudio de caso ciudad de Curauma”, Revista Invi, vol. 25, №69, pp. 103-123.

Maudos, J. (2018): "El impacto de la reestructuración bancaria sobre la concentración y exclusión financiera en Galicia”, Foro Económico de Galicia Documento 25/2018.

Rural Poverty and Inclusion Working Group (2001): Poverty and Social Exclusion in Rural Scotland, Report of the Rural Poverty and Inclusion Working Group, Scottish Government.

Silver, H. (1994): "Social Exclusion and Social Solidarity: Three Paradigms”, International Labor Review, vol. 133, pp. 531-77.

Subirats, J. (2005): “¿Es el territorio urbano una variable significativa en los procesos de inclusión y exclusión social?", Biblioteca virtual TOP, www.top.org.ar 